\title{
CONSECUENCIAS PROFESIONALES Y PERSONALES DE LA DEPURACIÓN FRANQUISTA EN EL PROFESORADO NORMALISTA: EL CASO ANDALUZ (1936-1941)
}

\author{
Professional and personal consequences of Franco's purge \\ of the teachers of teacher training schools: \\ the Andalusian case (1936-1941)
}

\section{Francisco Martín Zúñiga* e Isabel Grana Gil**}

Fecha de recepción: 05/02/2015 • Fecha de aceptación: 04/07/2015

Resumen: En esta oportunidad, profundizamos en la incidencia que tiene la depuración franquista en el caso concreto del profesorado de las Escuelas Normales de Magisterio Primario de Andalucía. Nuestro propósito no es sólo el de efectuar una interpretación de los datos cuantitativos, sino que prestamos especial atención a la incidencia que esta acción represiva tiene en su vida personal y profesional.

En la búsqueda de las fuentes documentales nos hemos encontrado con la dificultad de que los expedientes de depuración del profesorado normalista no se encuentran en el Archivo General de la Administración (AGA), lugar donde legalmente deben estar depositados. Esto nos ha obligado a la localización e interpretación de otras fuentes, como las publicadas en los Boletines Oficiales del Estado y las Provincias y las depositadas en los archivos Históricos de las universidades de Málaga, Granada y Sevilla, dado que son los rectores los responsables de tramitar la documentación generada por el proceso de depuración.

Respecto a las conclusiones, en las Escuelas Normales el número de profesoras y profesores es paritario y, sin embargo, la proporción de sancionadas es muy baja, incluso inferior a la de sus compañeras de los institutos de segunda enseñanza cuya plantilla es mínima, mientras que más del 34\% de los profesores son represaliados, como es habitual, por razones políticas, siendo especialmente duros con aquellos comprometidos activamente con la

\footnotetext{
* Universidad de Málaga. Facultad de Ciencias de la Educación. Dpto. de Teoría e Historia de la Educación. Campus de Teatinos, 29071. Málaga. España. fmartinz@uma.es

** Universidad de Málaga. Facultad de Ciencias de la Educación. Dpto. de Teoría e Historia de la Educación. Campus de Teatinos, 29071. Málaga. España. imgrana@uma.es
}

Cómo citar este artículo: Martín Zuñiga, Francisco e Grana Gil, Isabel. «Consecuencias profesionales y personales de la depuración franquista en el profesorado normalista: el caso andaluz (19361941), Historia y Memoria de la Educación, 3 (2016): 229-257. 
política republicana (alcaldes, concejales, diputados, directores generales de enseñanza,...). De todos modos, no hay unas diferencias muy significativas con la depuración de otros estamentos docentes.

Palabras clave: Franquismo. Depuración. Profesorado. Escuelas normales.

Abstract: In this article we focus on the purge carried out by Franco's regime against teachers of the teacher training schools in Andalucía. Our purpose is not only to provide an interpretation of the quantitative data, but to take a closer look at the way that this repressive action affected the personal and working lives of the teachers.

In our search for documentary sources we faced a handicap derived from the fact that the files of the teachers affected by the purge were not to be found in the General Archive of the Administration (AGA), where by law they should have been deposited. As a result we were forced to seek out and interpret alternative sources such as those published in the Official Bulletin of the State and the Provinces or those found in the historic archives from the universities of Malaga, Granada and Seville, where the rectors were responsible for processing the documentation generated by the purging process.

With regard to some of the conclusions reached, in the teacher training schools, whereas the ratio of male to female teachers was almost even, the proportion of women that were sanctioned was very low, lower even than their colleagues in secondary school, who were very few, meanwhile more than $34 \%$ of men were punished, usually for political reasons, special severity being taken against those actively related with republican politic (mayors, city councillors, deputies, general directors of education,...). Anyway, there are no significant differences with the purge of others educational sectors.

Keywords: Francoism. Purge. Teachers. Teacher training schools.

\section{INTRODUCCIÓN}

El estudio de la depuración franquista del profesorado ha experimentado un notable impulso en los últimos años, aunque aún quedan lagunas por cubrir. Este es el caso de las profesoras y profesores de las Escuelas Normales —normalistas-, si bien, investigaciones en curso auguran un incremento importante de publicaciones sobre la cuestión. ${ }^{1}$ En nuestro caso,

\footnotetext{
${ }^{1}$ Ya han aparecido algunas investigaciones como las de Fátima Ortega Castillo, Carmen Sanchidrián Blanco, Francisco Martín Zúñiga y Juan Manuel Fernández Soria, «La depuración del profesorado de las Escuelas Normales a partir de las resoluciones publicadas en el BOE» en Entre generaciones: educación, herencia y promesas, eds. J. L. Gaviria Soto, M. ${ }^{a}$ C. Palmero Cámara y P. Alonso Marañón (Burgos: Instituto Calasanz de Ciencias de la Educación y Sociedad Española de Pedagogía, 2012), 240-250; Isabel Grana
} 
analizamos la repercusión de dicha depuración en el profesorado de las Escuelas Normales de Magisterio Primario ${ }^{2}$ andaluzas, sin descartar que en un futuro no muy lejano saquemos a la luz lo acaecido en otras Escuelas. ${ }^{3}$

No nos basta con el análisis cuantitativo — proporción de sanciones; diferencias por sexos; comparación entre Escuelas Normales- del problema. Lo que realmente nos preocupa es detectar cómo repercute la represión en el plano profesional y privado de ese profesorado. Por ello, hablamos de personas concretas, con nombres y apellidos, en un intento de recuperarlas para la memoria histórica.

Es necesario puntualizar, en relación con lo anterior, que la depuración no sólo sanciona, sino que también ejerce una función preventiva con la intención de no «tolerar, ni menos a proteger y subvencionar a los envenenadores del alma popular primeros y mayores responsables de todos los crímenes y destrucciones que sobrecogen al mundo y han sembrado de duelo la mayoría de los hogares honrados de España». ${ }^{4}$ Es decir, se trata de silenciar cualquier conducta o atisbo ideológico contrario a los intereses de la dictadura. Ese silencio lleva al olvido y, sobre todo, a la ignorancia de aquellos que no han vivido los hechos. Es por ello que desde aquí queremos romper una lanza en favor de la memoria histórica, reivindicándola como un instrumento útil para comprender y decidir nuestro futuro, sin la intención de culpabilizar a nadie, sino, simplemente, conocer, aceptar y vislumbrar lo sucedido. ${ }^{5}$

Gil y Francisco Martín Zúñiga, «La depuración franquista del profesorado normalista malagueño» en VIII Encuentro internacional de investigadores del franquismo, eds. Carmen Molinero y Javier Tébar (Barcelona: Universidad Autónoma, 2013), CD ISBN 978-84-695-8654-9. Finalmente, sobre la temática que nos ocupa hay una primera aproximación, básicamente cuantitativa y fundamentada en datos todavía parciales extraídos del Boletín Oficial del Estado (BOE), en Isabel Grana Gil y Fátima Ortega Castillo, «La depuración de las Escuelas Normales de Andalucía» en Constitución de Cádiz. Genealogía y desarrollo del sistema educativo liberal/ XVII Coloquio de la SEDHE, eds. M. Gloria Espigado Tocino y Juan Gómez Fernández (Cádiz: Servicio de publicaciones de la Universidad de Cádiz, 2013), 449-458.

${ }^{2}$ Conviene recordar que en estos años la dictadura aún no ha derogado la Orden de la Dirección General de 30 de octubre de 1931 que establece la unión de las Escuelas Normales masculinas y femeninas en una sola Escuela mixta denominada Escuela Normal de Magisterio Primario, de ahí que sigamos manteniendo dicha denominación.

${ }^{3}$ De momento, sólo hay publicado un estudio de similares características, cfr. Carmen Agulló Díaz y Juan Manuel Fernández Soria, «La depuración franquista de las Escuelas Normales de Alicante, Castellón y Valencia», Revista de Educación, 364 (2014): 197-221.

${ }^{4}$ Cfr. Orden de 7 de diciembre de 1936. Boletín Oficial del Estado (BOE), p. 883.

${ }^{5}$ Cfr. Francisco Martín Zúñiga, Isabel Grana Gil y Carmen Sanchidrián Blanco, «La depuración franquista de los docentes: control y sometimiento ideológico del profesorado de instituto», Historia de la Educación, 29 (2010): 245. 
Partiendo de la finalidad planteada y de nuestra propia experiencia en este campo, creemos que la presente investigación nos va a permitir corroborar varias hipótesis: 1. ${ }^{a}$ El número y la proporción de profesores sancionados es muy superior con respecto a sus compañeras; $2{ }^{a}$ La represión del profesorado de las Normales es más dura debido a su responsabilidad en la formación del magisterio primario; 3. ${ }^{a}$ Existen diferencias porcentuales poco significativas en el número de sanciones entre las distintas escuelas normales andaluzas; $4 .^{\mathrm{a}} \mathrm{El}$ profesorado de mayor rango académico -numerario- es el más castigado; $5 .^{\mathrm{a}}$ Los cargos acusatorios son fundamentalmente de carácter político; $6 .^{a}$ Las sanciones más frecuentes son aquellas que implican la expulsión temporal o definitiva del personal docente de sus puestos; 7. ${ }^{\mathrm{a}}$ La represión franquista no se contenta con las sanciones administrativas propuestas en la depuración, sino que con frecuencia aplica castigos mucho más duros, como la cárcel o la pena de muerte.

Nos hemos encontrado con la sorpresa de que los expedientes de depuración del profesorado normalista no se encuentran depositados en el Archivo General de la Administración (AGA), lugar donde sí se custodian los de otros cuerpos docentes, ni en ningún otro fondo documental consultado hasta el momento. La dificultad mencionada nos ha obligado a la búsqueda e interpretación de otras fuentes primarias extraídas del Boletin Oficial del Estado (BOE), Boletines Oficiales de las Provincias (BOP), expedientes personales y demás documentación depositada en el AGA y los archivos Históricos de las universidades de Málaga (AHUMA), Granada (AHUGR) y Sevilla (AHUS), así como la documentación oficial (Libros de Altas y Bajas del personal docente, Actas del Claustro,...) generada por las propias Escuelas Normales de Magisterio Primario en aquellos años.

No vemos la necesidad de realizar un análisis pormenorizado de las distintas fases del proceso de depuración franquista, pues este es un tema abordado con rigor en numerosas publicaciones, algunas de las cuales citamos aquí. Sólo recordar que, inicialmente, «la Universidad queda encargada de hacer realidad los dictados de la Junta de Defensa Nacional con respecto al control del sistema de enseñanza». ${ }^{6}$ Por ese motivo, cuando la mencionada Junta adopta la primera medida de dejar «en suspenso todo

\footnotetext{
${ }^{6}$ Juan Luis Rubio Mayoral, «Sobre el control de la enseñanza en el distrito universitario de Sevilla (1936-1941)» en La recuperación de la memoria histórico educativa andaluza, Varios Autores (Málaga: Sarriá, 2011), 128.
} 
tipo de pruebas y exámenes», le encomienda también a los rectores que cuiden el «exacto cumplimiento de la presente orden en sus respectivos distritos universitarios». ${ }^{7}$

Siguiendo con esta dinámica, los niveles de enseñanza media y superior son regulados por dos Órdenes de 28 de agosto de 1936: la primera se dirige a los directores de los centros de Enseñanza Secundaria, Normales de Magisterio, Comercio, Industriales y Artes y Oficios, con el fin de que adopten las medidas oportunas "para que todos los servicios docentes y administrativos reanuden su marcha normal»; y en la segunda orden se especifica:

que los Rectorados de los distritos universitarios remitieran las propuestas de los cargos de Directores que convenía remover, [...] que los Gobernadores Civiles en cuanto a las capitales de provincias y los Alcaldes en cuanto a los demás municipios enviaran al rectorado informe personal sobre los antecedentes y conducta política y moral de todo el profesorado. ${ }^{8}$

Con las órdenes de 8 y 10 de noviembre de 1936 se crean las cuatro Comisiones Depuradoras ${ }^{9}$ y, en consecuencia, los rectores dejan de tener un protagonismo directo en la acción depuradora, pero siguen siendo testigos de excepción al ser los responsables, según la vigente Ley de Instrucción Pública de 1857, de la organización y administración de toda la enseñanza del distrito universitario que presiden.

De acuerdo con la normativa mencionada, es la Comisión de Depuración $C$, una por provincia, la que «recabará los informes, instruirá los expedientes oportunos y propondrá resoluciones sobre todo el personal adscrito a los Institutos, Escuelas Normales, de Comercio, Artes y Oficios [...]». ${ }^{10} \mathrm{El}$ expediente

\footnotetext{
${ }^{7}$ Boletín Oficial de la Junta de Defensa Nacional de España (BOJDN) Orden (O). 11 de agosto de 1936.

${ }^{8}$ Cfr., respectivamente, los BOJDN n. ${ }^{\circ} 13$, O. de 29 de agosto de 1936 y el n. ${ }^{\circ} 14$, O. 30 de agosto del mismo año.

${ }^{9} \mathrm{La}$ «A», destinada al personal docente universitario y con sede en Madrid; una «B»para el profesorado de las Escuelas de Ingenieros y Arquitectos; la «C» centrada en los docentes de Institutos de secundaria, Escuelas Normales, de Comercio, de Artes y Oficios, de Trabajo, Inspectores de Primera Enseñanza, Sección Administrativa y, en general, a todos los que dependieran de Instrucción Pública que no estuviesen incluidos en las demás, y, por último, la «D» encargada del Magisterio primario. Las dos últimas son de ámbito provincial, cfr. BOE, O. 1742/8 de noviembre de 1936, p. 838.

${ }^{10}$ Dicha Comisión está constituida por el Gobernador Civil, un profesor del Instituto de Secundaria, otro de la Escuela Normal, uno de Artes y Oficios o de Comercio y un vecino de la capital, cfr. BOE, O. $1742 / 8$ de noviembre de 1936, p. 838.
} 
completo con la resolución tomada, que puede ser desde la confirmación en el puesto del expedientado hasta la imposición de alguna de las sanciones que aparecen en la tabla 2, es elevado a la Comisión de Cultura y Enseñanza, quien propone a la Junta Técnica del Estado la resolución definitiva.

Finalmente, una vez constituido el primer Gobierno de Franco (1938), los asuntos sobre depuración pasan a la Oficina Técnico-Administrativa de Depuración, creada por la O. de 11 de marzo de 1938 - B.O.E de 19 de marzo-, hasta que finalmente, una vez que los golpistas han conquistado casi todo el territorio nacional, es la Comisión Superior dictaminadora de los expedientes de depuración - O. de 18 de marzo de 1939- la que asume las competencias de la anterior.

Carecemos de la documentación generada por las Comisiones $C$ andaluzas, pues como ya se ha dicho no hemos tenido acceso a las expedientes de depuración, de manera que los datos que ofrecemos se han elaborado a partir de los BOE, donde por ley han de publicarse todas las resoluciones de los expedientes de depuración, y de los informes emitidos por los rectores de las universidades de Granada y Sevilla a la Comisión de Cultura y Enseñanza, entre agosto y noviembre de 1936. De todos modos, la mayoría del profesorado de las Escuelas Normales estudiadas es expedientado antes de que se constituyan las mencionadas Comisiones, por lo que la carencia mencionada no afecta significativamente a los resultados de nuestra indagación.

Finalmente, refiriéndonos ya a la estructura del trabajo que presentamos, en un primer momento nos centramos en la interpretación cualitativa de los datos numéricos - total de sancionadas y sancionados, diferencias por sexo y categorías docentes,...- en la que no nos limitamos al profesorado de las distintas Escuelas Normales, sino que la comparación se hace extensible a otros cuerpos docentes con objeto de obtener una visión más completa del problema. En segundo lugar, ofrecemos una valoración de los tipos de cargos y sanciones, tratando de plasmar cómo afecta esa circunstancia en la vida personal y profesional de profesoras y profesores, apoyándonos en muchos casos en sus propias biografías.

\section{PROFESORADO CONFIRMADO Y SANCIONADO: APROXIMACIÓN COMPARATIVA}

El análisis que iniciamos es de una envergadura importante, dado que Andalucía cuenta en estos momentos con una población de 208 profesoras 
y profesores normalistas, lo que supone el $21 \%$ del total nacional (994). Además, conviene advertir que no nos limitamos a interpretar los resultados obtenidos en torno al profesorado mencionado, sino que, como ya se ha comentado, buscamos las similitudes y diferencias de la acción depuradora con respecto a otros cuerpos docentes.

Un factor que incide en la valoración de los datos es la propia fisonomía de las Escuelas Normales de Magisterio. Se regulan por la Orden de la Dirección General de Primera Enseñanza republicana de 30 de octubre de 1931, en la que se dictamina que las antiguas Escuelas Normales de Maestros y Maestras se fusionen en una sola y se integren por diez profesores y profesoras numerarios, tres especiales, los Regentes de las Graduadas Anejas y auxiliares para las tres secciones (letras, ciencias y pedagogía). Le corresponde ocupar la dirección del centro, de manera interina, al director o directora más antiguo, y la secretaría al profesor o profesora que ha tomado posesión de su puesto más recientemente. Asimismo se estipula que en el caso de existir más profesorado del necesario, los más nuevos deben solicitar traslado a otras escuelas en las que haya vacantes. En Málaga, por ejemplo, hay doce numerarios, seis por cada escuela, por lo que sobran dos que, en este caso, corresponden a la Escuela normal masculina. ${ }^{11}$

Esa reforma provoca una situación inédita hasta ese momento, y es que por primera vez los profesores de un centro público pueden ser dirigidos por una profesora y, por otro lado, posibilita la paridad de las plantillas con respecto al sexo. Esto último se aprecia claramente en la tabla 1, donde los datos nos muestran que a nivel estatal son 532 profesoras $(53,52 \%)$ frente a 462 profesores $(46,48 \%)$, mientras que en las Escuelas normales andaluzas la situación es la inversa pero con escasas diferencias; es decir, el 48,08\% son mujeres (100) y el 51,92 \% hombres (108), aunque en las Escuelas de Cádiz, Jaén y Málaga el número de ellas es superior, destacando especialmente la malagueña con un $68 \%$ de profesoras, y en Córdoba la proporción es al $50 \%$. En Granada y Sevilla la balanza se inclina a favor de los varones, con escasas diferencias, y únicamente en Almería y Huelva hay una mayoría significativa a favor del profesorado masculino.

${ }^{11}$ Cfr. Grana Gil y Martín Zúñiga, «La depuración franquista del profesorado normalista malagueño», 4. 
Tabla 1. Profesorado confirmado y sancionado en las Escuelas Normales de Andalucía (1936 a 1940)

\begin{tabular}{|c|c|c|c|c|c|c|c|c|}
\hline & Total & $\%$ Sexo & $\mathbf{C}$ & $\begin{array}{c}\% \text { de C } \\
\text { por sexo }\end{array}$ & $\begin{array}{c}\% \text { total } \\
\text { de C }\end{array}$ & $\mathbf{S}$ & $\begin{array}{c}\% \mathbf{S} \text { por } \\
\text { sexo }\end{array}$ & $\%$ total de $\mathbf{S}$ \\
\hline \multicolumn{9}{|c|}{ ALMERÍA } \\
\hline Profesoras & 9 & 39,13 & 8 & 88,89 & 42,11 & 1 & 11,11 & 25,00 \\
\hline Profesores & 14 & 60,87 & 11 & 78,57 & 57,89 & 3 & 21,43 & 75,00 \\
\hline Total & 23 & 100 & 19 & 82,61 & 100 & 4 & 17,39 & 100 \\
\hline \multicolumn{9}{|c|}{ CÁDIZ } \\
\hline Profesoras & 14 & 56,00 & 13 & 92,86 & 66,67 & 1 & 7,14 & 50,00 \\
\hline Profesores & 11 & 44,00 & 10 & 90,91 & 43,48 & 1 & 9,09 & 50,00 \\
\hline Total & 25 & 100 & 23 & 92,00 & 100 & 2 & 8,00 & 100 \\
\hline \multicolumn{9}{|c|}{ CÓRDOBA } \\
\hline Profesoras & 16 & 50,00 & 16 & 100 & 66,67 & 0 & 0 & 0 \\
\hline Profesores & 16 & 50,00 & 8 & 50,00 & 33,33 & 8 & 50,00 & 100 \\
\hline Total & 32 & 100 & 24 & 75,00 & 100 & 8 & 25,00 & 100 \\
\hline \multicolumn{9}{|c|}{ GRANADA } \\
\hline Profesoras & 15 & 48,39 & 13 & 86,67 & 56,52 & 2 & 13,33 & 25,00 \\
\hline Profesores & 16 & 51,61 & 10 & 62,50 & 43,48 & 6 & 37,50 & 75,00 \\
\hline Total & 31 & 100 & 23 & 74,19 & 100 & 8 & 25,81 & 100 \\
\hline \multicolumn{9}{|c|}{ HUELVA } \\
\hline Profesoras & 6 & 26,09 & 6 & 100 & 33,33 & 0 & 0 & 0 \\
\hline Profesores & 17 & 73,91 & 12 & 70,59 & 66,67 & 5 & 29,41 & 100 \\
\hline Total & 23 & 100 & 18 & 78,26 & 100 & 5 & 21,74 & 100 \\
\hline \multicolumn{9}{|c|}{ JAÉN } \\
\hline Profesoras & 11 & 52,38 & 11 & 100 & 55,00 & 0 & 0 & 0 \\
\hline Profesores & 10 & 47,62 & 8 & 80,00 & 45,00 & 2 & 20,00 & 100 \\
\hline Total & 21 & 100 & 19 & 90,48 & 100 & 2 & 9,52 & 100 \\
\hline \multicolumn{9}{|c|}{ MÁLAGA } \\
\hline Profesoras & 17 & 68,00 & 15 & 88,23 & 83,33 & 2 & 11,76 & 28,57 \\
\hline Profesores & 8 & 32,00 & 3 & 37,50 & 16,67 & 5 & 62,50 & 71,43 \\
\hline Total & 25 & 100 & 18 & 69,23 & 100 & 7 & 28,00 & 100 \\
\hline \multicolumn{9}{|c|}{ SEVILLA } \\
\hline Profesoras & 12 & 42,86 & 12 & 100 & 57,14 & 0 & 0 & 0 \\
\hline Profesores & 16 & 57,14 & 9 & 56,25 & 42,86 & 7 & 43,75 & 100 \\
\hline
\end{tabular}




\begin{tabular}{|c|c|c|c|c|c|c|c|c|}
\hline & Total & $\%$ Sexo & $\mathbf{C}$ & $\begin{array}{c}\% \text { de C } \\
\text { por sexo }\end{array}$ & $\begin{array}{c}\% \text { total } \\
\text { de C }\end{array}$ & $\mathbf{S}$ & $\begin{array}{c}\% \mathbf{S} \text { por } \\
\text { sexo }\end{array}$ & $\%$ total de S \\
\hline Total & 28 & 100 & 21 & 78,57 & 100 & 7 & 25,00 & 100 \\
\hline \multicolumn{9}{|c|}{ ANDALUCÍA } \\
\hline Profesoras & 100 & 48,08 & 94 & 94,00 & 56,71 & 6 & 6,00 & 13,95 \\
\hline Profesores & 108 & 51,92 & 71 & 65,74 & 43,29 & 37 & 34,26 & 86,05 \\
\hline Total & 208 & 100 & 165 & 78,47 & 100 & 43 & 20,67 & 100 \\
\hline \multicolumn{9}{|c|}{ ESPAÑA } \\
\hline Profesoras & 532 & 53,52 & 460 & 86,47 & 58,67 & 72 & 13,53 & 34,29 \\
\hline Profesores & 462 & 46,48 & 324 & 70,13 & 41,33 & 138 & 29,87 & 65,71 \\
\hline Total & 994 & 100 & 784 & 78,87 & 100 & 210 & 21,13 & 100 \\
\hline
\end{tabular}

Abreviaturas: $\mathrm{C}=$ Confirmados; $\mathrm{S}=$ Sancionados .

Fuente: Elaboración propia a partir del B.O.E. y documentación de los archivos mencionados.

Centrándonos ya en la repercusión de la acción represiva, el 20,67\% (43) del profesorado de las Escuelas andaluzas sufre algún tipo de sanción, siendo este porcentaje prácticamente igual al nacional (21,13\%), con 210 afectados - cfr. tabla 1-, y cinco puntos menos que el global de la comunidad Valenciana $(26,76 \%)$ que, de momento, es la única sobre la que podemos establecer comparaciones. ${ }^{12}$ En principio, la impresión es que en Andalucía el nivel de sanciones es similar al nacional, aunque aún faltan estudios del resto de las comunidades para conocer con exactitud la situación real en la que se encuentra dicha comunidad.

Refiriéndonos al total de normalistas sancionados y sancionadas (43), las profesoras sólo suponen el 13,95\%. Dicho de otro modo, en cuatro Escuelas (Córdoba, Huelva, Jaén y Sevilla) no hay sancionadas y en el resto únicamente cuentan con un caso o dos a lo sumo, como sucede en Granada y Málaga — ver tabla I- De todos modos, la situación es muy distinta a nivel nacional, donde el porcentaje de sancionadas es más del doble $(34,29 \%)$ - cfr. tabla $1-$ y el triple $(63,16 \%)$ si lo comparamos con los datos generales de las Escuelas valencianas donde, incluso, en valores absolutos son el doble las sancionadas - 12 de un total de 41 - en relación con sus compañeras andaluzas — seis de 100—. Para Agulló y Fernández Soria «el elevado

${ }^{12}$ Cfr. Agulló Díaz y Fernández Soria, «La depuración franquista de las Escuelas Normales de Alicante, Castellón y Valencia», 205. 
compromiso político y sindical de las mujeres — se refieren a las profesoras normalistas valencianas- explicaría este dato, cuestionando, además, el supuesto paternalismo de los depuradores». ${ }^{13}$

Por otro lado, resulta llamativo que siendo bastante superiores en número con respecto a otros estamentos docentes, no haya más castigadas. Por ejemplo, de las 100 profesoras existentes sólo seis (6,00\%) sufren algún tipo de sanción, mientras que de las compañeras de los institutos andaluces, que en estos momentos sólo son $39(9,26 \%)$ con respecto al total (420), se castiga a $11(28,95 \%)$, un porcentaje superior incluso al de la media nacional $(20,50 \%) .{ }^{14}$ Tampoco parece que existan grandes diferencias con respecto al magisterio andaluz, pues el mencionado porcentaje de profesoras de Escuelas Normales sancionadas es similar al de las maestras en Granada $(6,12 \%)$, Sevilla $(6,26 \%)$ y Málaga $(8,62 \%)$, mientras que dicha diferencia es algo mayor en el caso de Córdoba $(9,95 \%)$, Almería $(11,20 \%)$ y Huelva $(15,99 \%) .{ }^{15}$

Queda claro, por tanto, que las profesoras normalistas de Andalucía no representan, ideológicamente, un grave peligro para el régimen franquista. La mayoría, según los informes emitidos desde los rectorados, son consideradas «católicas y de derechas». De hecho, varias de ellas pertenecen o simpatizan con organizaciones religiosas como la Institución Teresiana, fundada por Pedro Poveda en 1911 para la promoción de la mujer desde la educación. Este es el caso Angustias Algarra Ramírez y M. ${ }^{a}$ Josefa Grosso en Córdoba; Pilar Jiménez Losa en Granada; Carmen Carbajo Prat y Heliodora

\footnotetext{
${ }^{13}$ Cfr. Agulló Díaz y Fernández Soria, «La depuración franquista de las Escuelas Normales de Alicante, Castellón y Valencia»: 206

${ }^{14}$ Cfr. Carmen Sanchidrián Blanco, Isabel Grana Gil y Francisco Martín Zúñiga, «Análisis y valoración de los expedientes de depuración del profesorado de instituto de segunda enseñanza en el franquismo", Revista de Educación, 356 (2011): 392, y Francisco Martín Zúñiga e Isabel Grana Gil, «La depuración del profesorado de instituto en Andalucía durante el franquismo (1937-1942)» en La recuperación de la memoria histórico-educativa andaluza, 93-94.
}

${ }_{15}$ Los datos de Granada y Sevilla se han extraído de Francisco Morente Valero, La escuela y el estado nuevo. La depuración del magisterio nacional (1936-1943) (Valladolid: Ámbito, 1997), 360, y de Sara Ramos Zamora, «Control y represión estudio comparado de los resultados de la depuración del magisterio primario en España», Revista Complutense de Educación, 17 (1), (2006): 176 y ss. Para el resto de provincias andaluzas sobre las que hay datos, cfr. Antonio Sánchez Cañadas, Memoria y dignidad; depuración y represión del magisterio almeriense durante la dictadura de Franco (Almería: Editorial Corduba, 2006), 162; Manuel Morente Díaz, La depuración de la enseñanza pública cordobesa a raíz de la Guerra Civil (Córdoba: El Páramo, 2011), 257 y 393-396; M. Reyes Santana, M. y J. J. de Paz Sánchez, La represión del magisterio republicano en la provincia de Huelva (Huelva: Diputación Provincial de Huelva, Servicio de Publicaciones, 2009), 540; María del Campo Pozo Fernández, «Aportación a la historia del magisterio malagueño: la depuración franquista» en La recuperación de la memoria histórico-educativa andaluza, 120. 
Cruz Artiaga en Jaén; María Carbajo Prat y M. ${ }^{a}$ Victoria Montiel Vargas en Málaga; y Josefa Amor Rico y Herminia del Pino Martín en Sevilla. ${ }^{16}$

Con quien sí muestra especial virulencia el aparato represor franquista es con el profesorado masculino de las Escuelas Normales andaluzas. De 108 profesores, 37 , el $34,26 \%$, son castigados, y si nos referimos a la totalidad de sancionados y sancionadas suponen el $86,05 \%$. Sorprende lo elevado de estas cifras al compararlas con los valores nacionales, donde la proporción de varones sancionados baja al 29,87\% — cfr. tabla 1-, y la disparidad es aún mayor si nos referimos a sus colegas en las Escuelas Normales valencianas, con un porcentaje de varones sancionados de once puntos menos $(23,33) .{ }^{17}$

Esa contundencia sancionadora se percibe también al establecer comparaciones con otro ámbitos docentes: el porcentaje de compañeros de instituto de segunda enseñanza sancionados es de catorce puntos menos $(21,47 \%)$ en Andalucía y de siete $(28,59 \%)$ si hablamos a nivel nacional. ${ }^{18}$ Así mismo, son menores los porcentajes de maestros sancionados en las escuelas públicas de Almería (27,50\%), Granada (27,77\%), Málaga (26,85\%), Córdoba $(26,18 \%)$ y Sevilla $(20,73 \%)$, y sólo Huelva se aproxima con el $34,15 \%$ al porcentaje mencionado de profesores normalistas represaliados. ${ }^{19}$

Por Escuelas Normales, en Córdoba, Huelva, Jaén y Sevilla el 100\% de los sancionados son varones; les siguen Almería y Granada, que soportan, respectivamente; el $75 \%$, Málaga con el 71,43\% y Cádiz que llega al 50\%. Si nos referimos al número de sancionados por sexo, el caso de Málaga es especialmente llamativo ya que al 62,50 \% de los varones, cinco, se les impone algún tipo de sanción, y eso que en esta escuela hay una amplia mayoría $(68 \%)$ de mujeres - 17 profesoras frente a ocho profesores-. Algo parecido sucede en Córdoba con ocho sancionados (56,25\%), mientras que en el resto

\footnotetext{
${ }_{16}$ Cfr. Ángela del Valle López, «Una propuesta educativa en las primeras décadas del siglo XX», en Historia de la Institución Teresiana (1911-1936), ed. Francisca Rosique (Madrid: Sílex Ediciones, 2014), 241-242.

17 Cfr. Agulló Díaz y Fernández Soria, «La depuración franquista de las Escuelas Normales de Alicante, Castellón y Valencia», 205.

${ }^{18}$ Cfr. Sanchidrián Blanco, Grana Gil y Martín Zúñiga, «Análisis y valoración de los expedientes de depuración del profesorado de instituto de segunda enseñanza en el franquismo», 392-392, y Martín Zúñiga y Grana Gil. «La depuración del profesorado de instituto en Andalucía durante el franquismo (1937-1942)», 94.

${ }_{19}$ Cfr. Morente Valero, La escuela y el estado nuevo, 360; Sánchez Cañadas, Memoria y dignidad, 162; Morente Díaz, La depuración de la enseñanza pública cordobesa, 257; Reyes Santana y de Paz Sánchez, La represión del magisterio republicano, 540; y Pozo Fernández, «Aportación a la historia del magisterio malagueño», 120.
} 
de Escuelas se oscila entre el 40 y 20\%, sorprendiendo Cádiz con sólo un profesor sancionado $(9,09 \%)$-cfr. tabla 1 -

En definitiva, para el franquismo el profesorado masculino de las Escuelas Normales de Andalucía, al contrario que sus compañeras, sí se considera un foco pernicioso del que hay que «extirpar de raíz — según la Orden mencionada de 8 de noviembre de 1936- esas falsas doctrinas que con sus apóstoles han sido los principales factores de la trágica situación a que fue llevada nuestra patria». En cierto modo, esa represión es comprensible pues, como veremos en su momento, algunos de ellos participan activamente en la política republicana - alcaldes, concejales, diputados y hasta directores generales de enseñanza- y para los golpistas eso implica «la separación inexorable de sus funciones magistrales» de acuerdo con la Orden de 7 de diciembre de 1936.

Pero el profesorado que despierta mayor recelo a los golpistas por su implicación política es el universitario ${ }^{20}$. Se le estigmatiza con el calificativo de «intelectual», que se convierte incluso en un cargo punible. No es casualidad que en plena guerra se editen libros como el de Enrique Suñer Ordóñez, Los intelectuales y la tragedia española (Burgos, 1937), o el de Constancio Eguía Ruiz, Los causantes de la tragedia hispana. Un gran crimen de los intelectuales españoles (Buenos Aires, 1938). ${ }^{21}$

\footnotetext{
${ }^{20}$ Para mayor profundidad sobre la depuración en la universidad, cfr. Marc Baldó Lacomba, «Represión franquista del profesorado universitario», Cuadernos del Instituto Antonio de Nebrija, 14 (2011): 31-51. Jaume Claret Miranda, El atroz desmoche. La destrucción de la universidad española por el franquismo (Barcelona, Crítica, 2006); Jaume Claret Miranda, «Cuando las cátedras eran trincheras. La depuración política e ideológica de la Universidad española durante el primer franquismo», Hispano Nova, 6 (2006); J. J. Carreras Ares y M. A. Ruiz Carnicer, (eds.). La Universidad española bajo el régimen de Franco (19391975) (Zaragoza: Institución Fernando el Católico, 1991); G. González Roldán, El nacimiento de la universidad franquista: la depuración republicana y franquista de los catedráticos de Universidad (Tesis doctoral, Madrid, Facultad de Geografía e Historia de la UNED, 2001, 2 vols); J. A. García Fraile e I. Masera Virosta, «Algunas reflexiones en torno al proceso de depuración del profesorado universitario tras la guerra civil» en La Universidad en el siglo XX. (España e Iberoamérica) (Actas del X Coloquio de Historia de la Educación, Murcia: Universidad, 1998), 515-522; Luis Enrique Otero Carvajal (dir.), La destrucción de la ciencia en España. Depuración universitaria en el franquismo (Madrid: Editorial Complutense, 2006); F. Pérez Pena, Exilio y depuración política en la Facultad de Medicina de San Carlos, (Madrid: Visión Net, 2005); J. L. Rubio Mayoral, «El profesorado de la Universidad de Sevilla. Aproximación al proceso de depuración política (1936-1939)», en Universidad y poder: problemas históricos, ed. M. ${ }^{a}$ Nieves Gómez García (Sevilla: GIHUS, 1993, 57-114); J. L. Rubio Mayoral, «La depuración de la cultura popular. La Universidad y el Ateneo de Sevilla en la censura de libros durante la guerra civil», en Educación Popular (Actas del VIII Coloquio Nacional de Historia de la Educación. Tenerife: Universidad de la Laguna, T. III, 1998), 251-266; y P. Zambrana Moral, Depuración política universitaria en el primer franquismo: algunos catedráticos de derecho (Málaga: Universidad de Málaga, 2001).
}

${ }^{21}$ Cfr. Claret Miranda, El atroz desmoche, 23 y ss. 
Esta especie de insidia provoca una mayor contundencia en los mecanismos de la purga universitaria. En ese sentido, en lugar de prorrogar el funcionamiento de las Comisiones $A$, tal como sucede con las restantes, a partir de 18 marzo de 1939 se encomienda su función a cuatro jueces instructores de turno - uno por cada universidad con mayor influencia republicana (Barcelona, Madrid y Valencia) y otro para el resto de centros-, por lo que al supuesto carácter administrativo y profesional del proceso de depuración se le añade el judicial. Estos jueces instructores son especialmente severos con las universidades mencionadas: por ejemplo, en la de Valencia es sancionado el $42 \%$ del profesorado ${ }^{22}$ y en la de Barcelona 135 profesores de todas las categorías son separados, lo que representaba más del $50 \%$ de la plantilla. ${ }^{23}$

Pero no les basta con judicializar la «purificación», pues aquellos catedráticos que han desempeñado altos cargos en los gobiernos republicanos son sancionados de oficio, sin esperar a las resoluciones de la Comisión o las sentencias de los jueces instructores, como sucede con Juan Negrín López, Fernando de los Ríos Urruti, José Giral Pereira, Luis Jiménez de Asúa y Gustavo Pittaluga Fattorini. Esa misma excepcionalidad se repite al finalizar la guerra, pues entre febrero y agosto de 1939 la Presidencia del gobierno publica varios decretos en los que se separa definitivamente de sus puestos a más de cuarenta catedráticos, ${ }^{24}$ entre los que destacamos a Pablo Azcárate Flórez, Felipe Sánchez Román, José Castillejo Duarte, Wenceslao Roces Suárez, Julián Besteiro Fernández, Domingo Barnés Salinas, Blas Cabrera Felipe, Honorato de Castro Bonel, José Sánchez Covisa, Américo Castro Quesada, Claudio Sánchez Albornoz, Niceto Alcalá-Zamora Castillo, Luis de Zulueta Escolano, Pedro Salinas Serrano, Blas Ramos Sobrino y un largo etcétera. La sanción no exige ninguna formalidad jurídica y se justificaba por los «antecedentes completamente desfavorables y en abierta oposición con el espíritu de la nueva España» de los purgados. ${ }^{25}$

22 Cfr. Claret Miranda, «Cuando las cátedras eran trincheras», 10.

${ }^{23}$ Datos extraídos del estudio de Baldó Lacomba, «Represión franquista del profesorado universitario», 33 y 34 .

${ }^{24}$ El ministro Sainz Rodríguez cifra en 1.101 los profesores universitarios depurados hasta 1939. Sólo respecto de los catedráticos universitarios hay constancia de más de 160 sanciones (1/3 del total). Cfr. Claret Miranda, «Cuando las cátedras eran trincheras», 10 y 12.

${ }^{25}$ Cfr. Ibid, 16 y 17. 
En síntesis, la maquinaria depuradora es más radical con el profesorado universitario. No le basta la acción administrativa de las Comisiones y recurre directamente a la vía judicial o a la sanción por decreto. Ello se justifica porque dicha institución es el foco de intelectuales que han aportado, en gran medida, los fundamentos ideológicos de la república y se han involucrado directamente en el gobierno de la misma.

Conviene recordar, no obstante, que un grupo numeroso de profesores universitarios - como ocurre en los otros cuerpos docentes- se adhiere al levantamiento y participa en los diferentes niveles de la naciente administración franquista y en la represión de sus propios compañeros de claustro. Un ejemplo de «colaboracionismo» lo tenemos, sin salirnos del entorno andaluz, en la universidad hispalense, ${ }^{26}$ donde el

profesorado coopera igualmente a este movimiento salvador prestando servicios en la siguiente forma: los de Medicina en Hospitales de sangre; los de Ciencias físico-químicas, en servicios químicos de guerra, observatorios astronómicos o de meteorología, laboratorios de mecánica, balística etcétera; los de Derecho, en la administración de justicia, así como asesores jurídicos [...]. ${ }^{27}$

Ello no significa que en la universidad de Sevilla no se apliquen sanciones; basta con leer el informe del rectorado de 28 de septiembre de 1936 donde aparecen ocho profesores suspendidos de empleo y sueldo ${ }^{28}$, a los que hay que sumar los «trasladados, los exiliados, los no renovados, los excedentes, los jubilados...» y a un fusilado, el auxiliar y diputado del Partido Socialista Obrero Español (PSOE), Rafael Calvo Cuadrado. ${ }^{29}$ Pero esto es una minucia comparado con lo que sucede, en palabras de Jaume Claret, en «la universidad violentada» de Granada, donde en los primeros días del golpe militar son asesinados el rector Salvador Vila Hernández, ${ }^{30}$

\footnotetext{
${ }^{26}$ Para mayor conocimiento sobre la depuración en la universidad sevillana, consúltese la obra citada de Rubio Mayoral, «El profesorado de la Universidad de Sevilla».

${ }^{27}$ Cfr. A.H.US, Leg. 1992. «Depuración del personal docente, administrativo y subalterno de la universidad de Sevilla». Citado también por Claret Miranda, El atroz desmoche, 230.

${ }^{28}$ Cfr. A.H.US, Leg. 1992. "Relación del personal docente dependiente de la universidad de Sevilla, propuesto a la comisión de Cultura y Enseñanza para que sean sancionados».

${ }^{29}$ Cfr. Claret Miranda, El atroz desmoche, 215, y Rubio Mayoral, «El profesorado de la Universidad de Sevilla», 59 .

${ }^{30}$ Para una aproximación a la biografía del considerado discípulo predilecto de Unamuno, cfr. Mercedes del Amo, Salvador Vila. El Rector fusilado en Viznar (Granada: Universidad de Granada, 2005).
} 
los catedráticos Joaquín García Labella, Rafael García Duarte Salcedo, Jesús Yoldi Bereau, el vicerrector José Polanco Romero y el auxiliar de anatomía y técnica anatómica y concejal de Izquierda Republicana, José Megías Manzano. ${ }^{31}$ Tampoco escapa de esta barbarie luctuosa el profesorado normalista, pero de ello hablamos en el siguiente apartado.

Lo que si quisiéramos aclarar es que el profesorado más penado por la depuración en las Escuelas Normales es el de la categoría docente superior, que en este caso es la de Numerario - funcionario—. ${ }^{32}$ Goza de mayor prestigio social y es sobre la que recae gran parte de la carga docente y puestos directivos. En el caso andaluz, esta categoría soporta el 53,49\% del total de las sanciones, siendo varones el 78,26\%, y las Escuelas más perjudicadas las de Almería, Córdoba y Granada. No obstante, sorprende la saña contra los Auxiliares, pues casi un tercio $(29,54 \%)$ sufre algún tipo de sanción, lo que probablemente se justifica por el hecho de que la finalidad de la depuración, como decíamos al principio, no es sólo punitiva sino que, además, presenta un carácter preventivo, es decir, impedir que se introduzcan en los establecimientos educativos corrientes ideológicas perniciosas para el régimen. Uno de los medios más eficaces para evitar dicha propagación es el de ejercer mayor control y dureza con los docentes noveles, los Auxiliares, que en su mayoría se ha incorporado a la actividad docente durante la República y, por tanto, se teme que estén más influenciados por los planteamientos educativos de aquélla. ${ }^{33}$ Por contra, el profesorado Especial (Dibujo, Francés, Música y Religión) apenas es represaliado.

En los institutos de enseñanza media sucede algo parecido, es decir, las categorías pertenecientes al funcionariado son las que sufren mayor atosigamiento. En Andalucía, entre catedráticos (34,93\%) y encargados de curso $(48,19 \%)$ sobrepasan el $83 \%$ de las sanciones, en tanto que en el marco nacional el mayor porcentaje corresponde a los catedráticos $(42,32 \%)$ seguidos de los encargados de curso $(38,27 \%) .{ }^{34}$ Por último, resulta llamativo

\footnotetext{
${ }^{31}$ Cfr. Claret Miranda, «Cuando las cátedras eran trincheras», 10. Con respecto a José Megías, cfr. Baldó Lacomba, «Represión franquista del profesorado universitario», 44.

${ }^{32}$ El origen de las tres categorías - numerario, especial y auxiliar- lo encontramos en el art. 36 del R. D. de 30 de agosto de 1914 (Plan «Bergamín»).

${ }^{33}$ Los datos ofrecidos en este párrafo son de elaboración propia a partir de BOE., los expedientes personales y demás documentación localizada en diversos archivos.

${ }^{34}$ Cfr. Martín Zúñiga y Grana Gil (2011). «La depuración del profesorado de instituto en Andalucía durante el franquismo (1937-1942)», 99; y Sanchidrián Blanco, Grana Gil y Martín Zúñiga, «Análisis y
} 
que esa tendencia no sea muy distinta a lo sucedido en las universidades, incluso respecto con aquellas que son más represaliadas, pues en la de Madrid los catedráticos sancionados son el 44,40\% y en la de Barcelona al $38,3 \% .^{35}$

Con esta aproximación a la incidencia de las sanciones por categorías docentes damos por concluida esta parte dedicada al análisis cuantitativo dedicado a la repercusión de la depuración franquista en el profesorado de las Escuelas Normales. Hemos tenido ocasión de comprobar que, en términos generales, el nivel de sanciones es similar al nacional, aunque aún faltan los estudios del resto de las comunidades autónomas, salvo la valenciana, para tener una visión más precisa del problema. Por sexos, las profesoras andaluzas son poco sancionadas con respecto a sus compañeras en general y con relación a otros cuerpos docentes, en tanto que en el caso de los profesores sucede todo lo contrario, cuestiones que comprenderemos mejor a continuación.

\section{REPERCUSIÓN DE LOS CARGOS Y SANCIONES EN EL PROFESORADO}

En principio, y de modo preventivo, la Junta de Defensa Nacional suspende de empleo y sueldo a todo aquel profesorado que considera sospechoso - O. de 28 de agosto de 1936-, pero conforme se va consolidando el «aparato depurador» aparecen nuevas sanciones-cfr. tabla 2-.

No pretendemos reducir nuestra exploración sobre las sanciones al mero dato numérico, sino que queremos poner nombres y apellidos a las profesoras y los profesores normalistas afectados, e incluso aportar algunos datos biográficos sobre sus implicaciones en la vida política republicana, relevancia en la difusión del conocimiento pedagógico o cualquier otro asunto de interés. En definitiva, se trata de rescatar del olvido a estas personas pues, como decíamos al principio, uno de nuestros propósitos es el de recuperar la memoria histórica en relación con la represión franquista del profesorado.

valoración de los expedientes de depuración del profesorado de instituto de segunda enseñanza en el franquismo», 390.

35 Cfr. Baldó Lacomba, «Represión franquista del profesorado universitario», 33 y 34. 
TABLA 2. Distribución del profesorado por el tipo de sanciones

\begin{tabular}{|c|c|c|c|c|c|c|}
\hline Sanciones & Profesores & $\%$ & Profesoras & $\%$ & Total & $\%$ \\
\hline $\begin{array}{l}\text { Inhabilitación para el desem- } \\
\text { peño de cargos directivos ( } 2 \text { a } \\
5 \text { años) }\end{array}$ & 2 & 75 & 1 & 25 & 3 & 9.10 \\
\hline $\begin{array}{l}\text { Inhabilitación para la Enseñan- } \\
\text { za (temporal o total) }\end{array}$ & 2 & 100 & 0 & 0 & 2 & 2,27 \\
\hline $\begin{array}{l}\text { Inhabilitación para la Enseñan- } \\
\text { za y desempeño de cargos di- } \\
\text { rectivos }\end{array}$ & 1 & 100 & 0 & 0 & 1 & 2,27 \\
\hline $\begin{array}{l}\text { Separación del cuerpo con baja } \\
\text { en el escalafón }\end{array}$ & 17 & 94.74 & 1 & 5.26 & 19 & 43.18 \\
\hline $\begin{array}{l}\text { Suspensión de empleo y sueldo } \\
(1 \text { mes a } 3 \text { años ) }\end{array}$ & 6 & 85.71 & 1 & 14.29 & 7 & 15,90 \\
\hline $\begin{array}{l}\text { Suspensión de empleo y sueldo } \\
\text { e Inhabilitación para el desem- } \\
\text { peño de cargos directivos. }\end{array}$ & 2 & 100 & 0 & 0 & 2 & 4,54 \\
\hline $\begin{array}{l}\text { Suspensión de empleo y sueldo, } \\
\text { Traslado fuera de la provincia, } \\
\text { Prohibición de solicitar vacantes } \\
\text { e Inhabilitación para el desem- } \\
\text { peño de cargos directivos }\end{array}$ & 4 & 80 & 1 & 20 & 5 & 11,63 \\
\hline Traslado fuera de la Provincia & 1 & 50 & 1 & 50 & 2 & 4,54 \\
\hline $\begin{array}{l}\text { Traslado fuera de la Provincia, } \\
\text { Prohibición de solicitar vacantes } \\
\text { e Inhabilitación para el desem- } \\
\text { peño de cargos directivos }\end{array}$ & 2 & 66.66 & 1 & 33.33 & 3 & 6,82 \\
\hline Total general & 37 & 86.36 & 6 & 13.64 & 43 & 100 \\
\hline
\end{tabular}

Fuente: Elaboración propia a partir del B.O.E. y documentación de los archivos mencionados.

La más dura de todas las sanciones es la inhabilitación para la enseñanza (temporal o total) - cfr. tabla 2-, dado que supone la prohibición absoluta del ejercicio legal de la docencia. Se aplica al profesorado con especial significación en la política republicana o por ser familia de algún político relevante, como sucede con el profesor de la Escuela Normal de Córdoba Leopoldo Fernández Castillejo, hijo del alcalde republicano de dicha ciudad José Fernández Jiménez. Otro inhabilitado permanente es Eloy Vaquero Cantillo, una de las figuras más notables desde el punto de vista político en la Córdoba republicana -Alcalde en la primavera de 1931, Diputado y 
Ministro de Gobernación y de Trabajo-que se exilia a Gibraltar en primera instancia y nunca vuelve a España. ${ }^{36}$ Finalmente, Guillermo Álvarez García, de la Normal sevillana, es inhabilitado para la enseñanza durante un año. ${ }^{37}$

La separación definitiva del cuerpo y baja en el escalafón es la sanción que se impone con más frecuencia. En concreto, en las Normales andaluzas la sufren 17 profesores y una profesora $(41,86 \%)$ - cfr. tabla 2 - que son considerados políticamente peligrosos o que no se han presentado al requerimiento de la correspondiente Comisión de depuración. ${ }^{38}$ Dentro de este grupo recordamos a:

- Vicente Pertusa Périz, amigo de Antonio Gil Muñiz, con quien publica La Pedagogía Moderna, ${ }^{39}$ uno de los manuales más usados en las Escuelas Normales de aquella época y considerado una excepción dentro de la mediocridad existente en esos momentos, donde la mayoría de los textos eran transcripciones literales de autores extranjeros. ${ }^{40}$

Fue condenado, pese a ser sacerdote y amigo de Pedro Poveda, ${ }^{41}$ fundador de las «Teresianas», por dirigir la Escuela Normal de Málaga desde el golpe de estado hasta la toma de la ciudad por los franquistas a principios de febrero de 1937. En principio es suspendido de empleo y sueldo durante seis meses por Orden de 10 de junio de 1937, pero al no presentarse en su puesto por estar encarcelado se le aplica el art 171 de la Ley Moyano de 1857 y se le separa definitivamente en la Orden de 10 de enero de 1940. Al parecer fallece en la cárcel. ${ }^{42}$

\footnotetext{
${ }^{36}$ Cfr. A.H.US, Leg. 3319, carp. 1 y Morente Díaz, La depuración de la enseñanza pública cordobesa, 678 y ss.

${ }^{37}$ Cfr. A.H.US., Leg. 3334.

${ }^{38}$ En este caso, simplemente se les aplica el art. 171 de la todavía vigente Ley de Instrucción Pública de 9 de septiembre de 1857- Ley Moyano-, donde se expone que «Los Profesores que no se presenten a servir sus cargos en el término que prescriban los reglamentos, o permanezcan ausentes del punto de su residencia sin la debida autorización, se entenderá que renuncian sus destinos».

39 Esta obra se publica inicialmente en la imprenta de la Escuela Profesional Salesiana de Arte de Málaga en 1920 y consta de tres volúmenes: Tratado de la Educación, Tratado de la Enseñanza e Historia de la Educación.

${ }^{40}$ Cfr. Antonio Viñao Frago, «La Historia de la Educación en el siglo XX. Una mirada desde España», Revista Mexicana de Investigación Educativa, 7 (15), (2002): 230

${ }^{41}$ Cfr. Flavia Paz Velázquez, Cuadernos biográficos. Pedro Poveda, (Madrid: Narcea, 2002), 22

42 Cfr. María Josefa Rivera Sánchez, Las escuelas normales de Málaga (1846-1992), (Málaga: Delegación provincial de Málaga de la Consejería de Educación y Ciencia de la Junta de Andalucía, 1995), 151; Morente Díaz, La depuración de la enseñanza pública cordobesa, 693; Grana Gil y Martín Zúñiga, «La depuración franquista del profesorado normalista malagueño», 10.
} 
- Antonio Martínez Virel (1890-1985), pintor nacido en Badajoz, que desarrolla su actividad pictórica básicamente en la ciudad de Málaga alternándola con la docencia en la Escuela Normal, donde obtiene la plaza de profesor especial de dibujo en 1917. Retratista de la burguesía malagueña y autor de escenografías en los teatros Cervantes y Vital Aza. En 1929 participa en la Exposición Iberoamericana de Sevilla, con un retrato de la hija del novelista Salvador González Anaya, y colabora en la proyectada en 1931 por la Real Academia de San Telmo, junto a los artistas Moreno Carbonero, José Nogales, Fernando Labrada, Blanco Colis y López Mezquita. Entre sus cuadros más famosos destacan En la fragua, Solera, Cobre y fruta, Florero con calas...

Activista de izquierdas, firma junto a García Lorca, Alberti y otros artistas e intelectuales un manifiesto de adhesión al Frente Popular, publicado en El Mundo Obrero el 15 de febrero de 1936. Este activismo le supone, en principio, la suspensión de empleo y sueldo por la O. de 10 de junio de 1937, hasta que la Comisión de la Cultura y la Enseñanza le separa de su cargo y es encarcelado. Murió el 19 de julio de 1985 a la edad de 95 años. ${ }^{43}$

- Antonio Quintana Serrano, profesor especial de dibujo y francés en la Escuela Normal de Málaga desde 1912. Candidato del PSOE por Málaga capital en las elecciones generales de 1933, sin resultar elegido, es separado de su cargo con baja en el escalafón y encarcelado al ser tomada la ciudad por los golpistas. ${ }^{44}$

- Antonio Gil Muñiz nacido en Ceuta el 31 de marzo de 1892, aunque pronto se traslada a Málaga. Estudia en la Escuela Superior de Magisterio, sección ciencias, donde recibe la influencia del mundo cultural de la Institución Libre de Enseñanza (ILE). Pensionado por la Junta de Ampliación de Estudios viaja a Francia, Bélgica y Suiza para ampliar sus conocimientos de Psicología y Pedagogía.

Católico, no defiende el laicismo, pero es contrario a la confesionalidad en la educación, y pertenece al moderado Partido Republicano

${ }^{43}$ Cfr. J. M. Ocaña, «Tiempo pasado: Pintor Martínez Virel» El Sur digital (24/01/2007); H. Jiménez Gómez, Alberti y García Lorca: La difícil compañía (Sevilla: Ed. Renacimiento, 2009), 242; Grana Gil y Martín Zúñiga, «La depuración franquista del profesorado normalista malagueño», 10-11.

${ }^{44}$ Cfr. Rivera Sánchez, Las escuelas normales de Málaga (1846-1992), 151. 
Autónomo de Córdoba. Destaca por su labor como Director de la Escuela Normal del Magisterio Primario de Córdoba, donde pone en marcha el "plan profesional» del magisterio de 1931, prestando especial interés a la enseñanza de párvulos. Dirige la Revista de Escuelas Normales y a nivel político ostenta la Dirección General de Primera Enseñanza en 1935.

Ocupa un lugar destacado en nuestra historia de la educación contemporánea como estudioso y divulgador de la ciencia pedagógica. Publica diversos manuales usados como libros de texto en las Escuelas Normales hasta bien entrados los años sesenta. En concreto, nos referimos, entre otros, a su obra Estudios pedagógicos modernos -tres tomos-, publicada en Málaga por la Librería Denis hasta 1965, que es una reelaboración de la obra ya citada que escribe con el desaparecido Pertusa.

El golpe militar le sorprende de vacaciones en Málaga, lo que le obliga a presentarse en la Escuela Normal de dicha ciudad. Por ese motivo es depurado dos veces: en la primera, por el rectorado de Granada, de donde depende la Escuela malagueña, es suspendido de empleo y sueldo durante seis meses por la O. de 10 de junio de 1937; y en la segunda, por el rectorado de Sevilla, al que está adscrita la Normal cordobesa, se le acusa de relacionarse con la ILE y de masón. ${ }^{45}$ Finalmente, es sancionado con separación definitiva por O. de 4 de diciembre de 1939 y encarcelado en el penal del Puerto de Santa María. Con posterioridad es desterrado a Ansó (Pirineo oscense) de donde vuelve en 1942 para instalarse en Málaga. Su expediente es revisado en 1946 y se le rebaja la sanción a traslado forzoso a la Escuela Normal de Málaga $e$ inhabilitación para cargos directivos y de confianza, pese a lo cual, una vez habilitado, llega a ser director de la misma desde 1957 hasta su jubilación en 1962. Fallece el 13 de marzo de $1965 .{ }^{46}$

\footnotetext{
${ }^{45}$ Cfr. A.H.US, leg. 3155, carpeta 1.

${ }^{46}$ Para más información sobre este autor, cfr. Grana Gil y Martín Zúñiga, «La depuración franquista del profesorado normalista malagueño», 11-12; Ana Estrella Hernández Munilla, Aproximación a la vida y el pensamiento pedagógico de Gil Muñiz (Málaga: Universidad de Málaga 1996); Juan Holgado Barroso, «Antonio Gil Muñiz», en Estudios de historia de la educación andaluza: textos y documentos, (siglos XVIII, XIX y XX)», coord. María Isabel Corts Giner y María Consolación Calderón España (Sevilla: Universidad de Sevilla, Secretariado de Publicaciones, 2008), 239-243, y Morente Díaz, La depuración de la enseñanza pública cordobesa, 696.
} 
- Otro profesor separado de la Escuela cordobesa es Francisco Castro Zafra, fundador del Ateneo de Córdoba en enero de 1931 y militante del partido Republicano Radical Socialista. Es detenido al principio de la guerra y a finales de 1942 se revisa su expediente y se le vuelve a ratificar la sanción, hasta que en 1952 se le readmite en el servicio con traslado forzoso a Jaén durante tres años e inhabilitación para cargos directivos y de confianza. ${ }^{47}$

- Ramón Carreras Pons nace en la Junquera (Gerona) en 1893 milita en el partido Republicano Autónomo de Córdoba. Tras las elecciones de abril de 1931, es elegido presidente de la diputación de cordobesa y diputado a cortes en las de junio. En octubre de 1934 Lerroux le designa Comisario General de Cataluña, hasta enero de 1935, fecha en que dimite y pasa a ser sucesivamente Gobernador Civil de Sevilla y Zaragoza. A partir de las elecciones de febrero del 36 se orienta hacia Unión Republicana. La guerra los sorprende a él y a su esposa Julia Rodríguez, también profesora de la Escuela Normal de Córdoba, de vacaciones en La Junquera, y al no poder regresar se incorporan a la Escuela Normal de Albacete. En 1939 su esposa vuelve a Córdoba y es confirmada en su cargo, mientras él huye hacia la frontera siendo apresado y encarcelado hasta 1941, sin bien en 1937 se le separa definitivamente. Jamás vuelve a ejercer en la enseñanza pública a pesar de solicitar la revisión de su expediente en 1955 y $1962 .{ }^{48}$

- De la Normal sevillana son separados definitivamente dos parejas de hermanos: por un lado, Ramón y Andrés González-Sicilia y de la Corte, donde destaca el primero por ser elegido diputado y Director General de Primera Enseñanza, que sería considerado «izquierdista, masón y revolucionario»; y por otro, José y Manuel León Trejo «de reconocida actuación izquierdista», sobre todo José como concejal del ayuntamiento de la Sevilla y miembro del Partido de Unión Republicana. Ambos fueron detenidos y fusilados al iniciarse la guerra. ${ }^{49}$

\footnotetext{
47 Morente Díaz, La depuración de la enseñanza pública cordobesa, 679.

48 Morente Díaz, La depuración de la enseñanza pública cordobesa, 691.

49 Cfr. A.H.US, Leg. 1992. Puede completarse la información en Alejandro Ávila Fernández y Juan Holgado Barroso, «La formación inicial y permanente del magisterio primario en Andalucía durante los siglos XIX y XX» en Estudios de historia de la educación andaluza, 148 y ss.
} 
- Agustín Escribano Escribano, director de la Escuela Normal de Granada durante la República, es fusilado el 11 de septiembre de 1936 y un mes más tarde — O. de 26 de octubre de 1936- llega, ironías de la vida, la comunicación de su destitución como director de la citada Escuela. ${ }^{50}$

- También se separa en esa Escuela a Cándido López Uceda -O. de 19 de mayo de 1937-. Numerario de metodología de las Ciencias Naturales, es encarcelado e indultado con ocasión de la festividad del Corpus Christi en 1937. No obstante, sus ideas izquierdistas le hacen inadecuado "para seguir desempeñando la función docentes que hasta ahora tenía»; Daniel Ferbal Campo - O. de 20 de mayo de 1937-, profesor Especial de Francés; Luisa Estévez Fernández — O. de 12 de junio de 1937-, Auxiliar de Labores, y Raimundo Torres Blesa —O. de 19 de junio de 1937-, catedrático encargado de Organización Escolar. ${ }^{51}$

- Andrés López Gálvez de la Normal gaditana y Antonio Pasagali Lobo de la de Jaén. Diputado, este último, en 1936, forma parte de distintas comisiones del gobierno, es separado al no presentarse y fallece exiliado en Méjico. ${ }^{52}$

- Por último, Enrique Esbrí Fernández (1895-1936) que nace en Madrid y en 1917 toma posesión de la plaza de numerario de Gramática y Literatura en la Escuela Normal de Jaén. Comprometido con la educación popular, participa en las clases de alfabetización y funda la primera biblioteca municipal que es desmantelada tras la guerra. En 1929 se afilia al PSOE y a la UGT y desarrolla una intensa labor difundiendo el ideario del socialismo, como nos muestra en La lucha de clases, su obra más emblemática. En enero de 1931 es nombrado director de la Escuela, cargo al que renuncia por ser elegido ese mismo año diputado por el PSOE, y en 1936 se traslada a la Escuela Normal de Murcia. En los primeros días de la guerra, estando presidiendo el $4 .^{\circ}$ Tribunal de oposiciones de Magisterio que se celebran en León, es detenido,

\footnotetext{
${ }^{50}$ Cfr. A.H.UGR. Leg. 1329 y Miguel A. López, La Escuela Normal de Granada (1846-1970) (Granada: Universidad de Granada, 1979), 191.

${ }^{51}$ Cfr. A.H.UGR. Leg. 1329 y López, La Escuela Normal de Granada (1846-1970), 191.

${ }^{52}$ Cfr. Isabel Sancho Rodríguez, La Escuela Normal de Jaén (1843-1940) (Jaén: Servicio de Publicaciones del Ayuntamiento de Jaén, 1999), 662-663, vol. II.
} 
ejecutado y enterrado en la cuneta de algún camino en torno al 26 de julio de $1936 . .^{53}$

La segunda sanción más impuesta (32\%) es la suspensión de empleo y sueldo de un mes a tres años. Está pensada para dar un escarmiento, amedrentar o asegurar el total sometimiento del personal docente ante la amenaza de poder perder el empleo temporalmente. Este castigo lo sufren, entre otros, Francisco González Ponce, Juan Martínez Jiménez, Horacio Oliva Flores y Nicolás Robles Gómez de la Escuela Normal de Huelva, junto con José Fernández Jiménez y Sancho Martínez Espinar de la Normal cordobesa. Además, es frecuente que la suspensión vaya acompañada de otras sanciones como el traslado forzoso o la inhabilitación para el desempeño de cargos - cfr. tabla 2 -.

El traslado forzoso, dentro o fuera de la provincia, y con prohibición de solicitar vacantes $(22,20 \%)$ significa una verdadera pena de destierro. Con esta sanción se pretende alejar al profesorado de su área de influencia política. En esta situación se encuentra la profesora de Metodología de las Matemáticas de la Escuela Normal malagueña Encarnación Sánchez Picazo, que es trasladada fuera de la provincia por su militancia en el partido comunista y participar activamente como miliciana en patrullas mixtas y comités durante la guerra. ${ }^{54}$ También sufre dicha sanción Luisa Pueo Costa, numeraria de historia de la Escuela Normal granadina y secretaria de la Residencia de Señoritas Normalistas, que es trasladada a la de Palencia desde junio de 1937 a diciembre de 1939, siendo su «delito» el de ser la esposa de Agustín Escribano Escribano, profesor fusilado del que hemos hablado anteriormente. ${ }^{55}$

La inhabilitación para el desempeño de cargos directivos se aplica muchas veces junto con el traslado fuera de la provincia y la sanción de suspensión de empleo y sueldo durante un periodo determinado de tiempo. Recae sobre el profesorado sospechoso de "pasividad y tibieza en la Adhesión al Glorioso Movimiento Nacional». Se le aparta, efectivamente, de los puestos de decisión y poder por no demostrar fehacientemente su adhesión al nuevo régimen, aunque entendiendo que puede ser útil para la enseñanza siempre que se le mantenga vigilado y controlado de cerca por personas afectas al

\footnotetext{
53 Cfr. Sancho Rodríguez, La Escuela Normal de Jaén (1843-1940), 669-670.

${ }^{54}$ Cfr. Antonio Nadal, «Experiencia psíquica sobre las mujeres marxistas malagueñas. Málaga 1939», Baetica, Estudios de Arte, Geografía e Historia, 10 (1987): 369.

55 Cfr. A.H.UGR. Leg. 1329, y López, La Escuela Normal de Granada (1846-1970), 191.
} 
mismo. Padece esta sanción, por ejemplo, la profesora de la Escuela normal de Málaga M. ${ }^{a}$ Victoria Montiel que, como directora de la mencionada escuela, se lamenta en la sesión del claustro de 13 de agosto de 1936 de «los dolorosos sucesos que vienen desarrollándose desde el día 18 de julio último con motivo de la subversión, estimando que en estos momentos más que nunca debe prestarse una leal adhesión al régimen y al gobierno legalmente constituido". ${ }^{56}$ Probablemente esta adhesión al gobierno republicano le cuesta la inhabilitación para el desempeño de cargos directivos, sin valer como atenuante el informe favorable del claustro o que hubiese sido suspendida de empleo y sueldo — desde agosto de 1936 a febrero de 1937- por el gobierno republicano. Tampoco sirve de mucho que en la sesión de 10 de febrero de 1937 el claustro manifieste su adhesión al régimen franquista:

Tanto la Srta. Montiel, como la mayoría de los concurrentes a la reunión, se expresaron en elevados tonos patrióticos, haciendo destacar sus elogios al glorioso Ejército Nacional, por haber logrado la liberación de Málaga, después de siete meses de cautiverio indescriptible desarrollado por las hordas marxistas. ${ }^{57}$

En definitiva, es sancionada por ambos bandos pero pronto es rehabilitada.

Por último, en lo que se refiere a la distribución de las sanciones por sexo, en los varones hemos visto que predomina la separación definitiva $y$ baja en el escalafón y la suspensión de empleo y sueldo, pues se considera un riesgo que algunos de ellos continúen con su labor docente, mientras que en el caso de las pocas profesoras sancionadas se dan tres casos de traslado forzoso fuera de la provincia al imaginar, suponemos, que la militancia de izquierdas o ser la esposa de un profesor fusilado puede ocasionar una mala influencia en el entorno más inmediato.

Se diferencian de las profesoras de Instituto en que proporcionalmente éstas presentan datos similares a sus compañeros en lo que se refiere a la separación y se las sanciona más con la inhabilitación para cargos directivos $y$ de confianza, lo que evidencia el deseo franquista de reducir la presencia de

\footnotetext{
${ }^{56}$ Cfr. Libro de Actas, Claustro de la Escuela Normal de Málaga (1935-1945) en «Sesión de 13 de agosto de 1936», A.H.UMA.

${ }^{57}$ Cfr. Libro de Actas, Claustro de la Escuela Normal de Málaga (1935-1945) en sesión de 10 de febrero de 1937.
} 
las profesoras en los puestos de dirección, ${ }^{58}$ aunque el caso de las profesoras normalistas es distinto, ya que con el nuevo régimen se vuelven a separar las Escuelas Normales en femeninas y masculinas y, por lo tanto, hacen falta mujeres para dirigir dichas instituciones, lo que exige un mayor control en su elección.

\section{EPÍLOGO}

El estudio que acabamos de concluir aporta una visión bastante completa sobre la repercusión de la depuración franquista en el profesorado de las Escuelas Normales de Magisterio andaluzas, tanto en lo que se refiere a resultados globales, diferencias por sexos, categorías docentes, repercusión en cada una de esas Escuelas y afectación en las circunstancias personales y profesionales de dicho profesorado.

Es oportuno recordar que esta investigación cubre un hueco importante en el estudio de la depuración franquista del profesorado en la Comunidad Autónoma de Andalucía. De momento se han publicado varios trabajos, los cuales citamos en este artículo, sobre las secuelas de la acción represiva en el magisterio primario de la mayoría de las provincias, los institutos de enseñanza secundaria y las dos universidades - Granada y Sevilla - existentes en esos momentos. Pero sobre el caso de las Escuelas Normales solo existen estudios parciales sobre Córdoba, Jaén, Málaga, Sevilla y uno general en el que se aporta una primera aproximación que se completa ampliamente en la presente monografía.

Gran parte de nuestro trabajo ha consistido en comparar los datos obtenidos con los publicados sobre la represión docente en otros niveles del sistema educativo, lo que nos ha permitido establecer una serie de diferencias y similitudes que aportan, como luego comentaremos, una mejor comprensión del problema, sin perder de vista que nuestra investigación cubre una porción importante del mapa aún incompleto de la purga franquista del profesorado normalista, pues Andalucía cuenta en estos momentos con

\footnotetext{
${ }^{58}$ Cfr. Sanchidrián Blanco, Grana Gil y Martín Zúñiga, «Análisis y valoración de los expedientes de depuración del profesorado de instituto de segunda enseñanza en el franquismo», 389, e Isabel Grana Gil, «La depuración de las profesoras de instituto en España durante el franquismo. Análisis de expedientes» en Mujeres y educación. Saberes, prácticas y discursos en la historia, dirs. C. Flecha, M. Núñez y M. ${ }^{a}$ J. Rebollo (Sevilla: Miño y Dávila, 2005), 473 y ss.
} 
una nómina de 208 profesoras y profesores, lo que supone el $21 \%$ del total (994) nacional.

Inicialmente, nos encontramos con la sorpresa de que los expedientes de depuración del profesorado normalista no se encuentran depositados en el Archivo General de la Administración, lo que nos ha obligado a la búsqueda e interpretación de otras fuentes que suplan dicha insuficiencia. Tampoco hemos localizado la documentación generada por las Comisiones $C$ de depuración, aunque, como expresamos al inicio de este trabajo, la mayor parte del profesorado estudiado es expedientado antes de que se constituyan las mencionadas Comisiones en noviembre de 1936, por lo que la carencia mencionada no afecta significativamente a los resultados de nuestra indagación. De todos modos, dichas carencias han tenido una consecuencia muy positiva, la de sacar a la luz el rico patrimonio histórico-educativo que sobre esta temática existe en los fondos de los Archivos Históricos de las universidades de Granada, Málaga y Sevilla.

Ciñéndonos a las hipótesis planteadas, queda demostrado que el número de profesores sancionados en Andalucía supera con creces al de sus compañeras, y eso que la proporción de unos y otras por Escuela Normal es similar. Esto no es nada nuevo, es algo que se repite en los diversos estudios publicados hasta el momento sobre la depuración franquista del profesorado, pero lo peculiar de nuestro caso es que el porcentaje de profesores de Escuelas Normales andaluzas castigados supera al de sus compañeros a nivel nacional, así como al de otros cuerpos docentes - maestros y profesores de institutos de segunda enseñanza-, tanto a nivel andaluz como nacional; sólo quedan por debajo de los universitarios. La causa de esta mayor represión se debe, principalmente, a la implicación en la política republicana de varios de ellos como militantes de partidos de izquierdas, alcaldes, concejales, diputados, directores generales de primera enseñanza, ministros, etc.

En contraposición, las profesoras normalistas de Andalucía, exceptuando a Encarnación Sánchez Picazo que milita en el partido comunista, no representan un peligro para el régimen franquista. De hecho, son menos sancionadas que sus compañeras de segunda enseñanza, pese a que aquellas son muy superiores en número. Ideológicamente, tal como se especifica en los informes emitidos por los rectores a la Comisión de Cultura y Enseñanza, se las considera mayoritariamente católicas y de derechas. Algunas pertenecen a instituciones religiosas como las Teresianas, aunque ello no libra a 
una de ellas de ser represaliada por los golpistas - Victoria Montiel_. En la mitad de las Escuelas andaluzas (Córdoba, Huelva, Jaén y Sevilla) no hay sancionadas y en el resto únicamente cuentan con un caso o a lo sumo dos, como sucede en Granada y Málaga. No obstante, esta dinámica no se puede generalizar al resto del territorio nacional, pues hemos tenido ocasión de comprobar que las profesoras de las Escuelas Normales valencianas son más sancionadas que sus compañeros debido a su activismo sindical.

Los datos analizados no parece que corroboren de modo generalizado la hipótesis planteada de que «la acción depuradora es más rigurosa con el profesorado normalista» por ser, básicamente, el responsable de formar a maestros y maestras, piezas fundamentales en la inculcación de los ideales del nacional-catolicismo en la población escolar. En los datos comparativos se observa que la represión de este profesorado en Andalucía no es más dura que la de otros colectivos de la enseñanza pública; por ejemplo, en la segunda enseñanza el porcentaje del total de sancionados y sancionadas es incluso mayor, tanto a nivel andaluz como nacional, y en el magisterio primario el promedio es también superior en los valores estatales y sin apenas diferencias en los datos de la Comunidad andaluza. Sí parece que se cumple la hipótesis anterior cuando nos referimos exclusivamente a los varones, pues sus promedios de sancionados son bastante superiores a los de sus compañeros de segunda enseñanza y escuelas de primaria y similar al de los de universidad, salvo si los confrontamos con las universidades de Madrid, Barcelona y Valencia, donde se separa de sus puestos a casi la mitad de los profesores.

Constatamos que «la categoría docente más castigada es la de los funcionarios de mayor rango», que en el caso de las Escuelas Normales son los numerarios. Sucede lo mismo en los institutos de segunda enseñanza, con los catedráticos y agregados de curso, y en las universidades con los catedráticos. La razón de esta especial saña radica en que esas categorías son la que gozan de mayor prestigio social y, por tanto, sus miembros pueden ejercer una influencia clara entre sus conciudadanos, y muy especialmente desde la política, como se manifiesta en la nómina de profesores numerarios y catedráticos de universidad vinculados, en mayor o menor medida, con los gobiernos republicanos. Sin embargo, sorprende que la categoría más baja en el escalafón normalista, los Auxiliares, soporte casi el $30 \%$ de las sanciones. Parece que hay un cierto temor a que los docentes noveles, los que se han incorporado bajo el amparo de los planteamientos educativos republicanos, puedan ejercer una influencia perniciosa en las aulas. 
Que «los cargos son fundamentalmente de carácter político» es otra de las suposiciones que se ha validado en numerosas investigaciones y que aquí se ratifica, pues prácticamente la totalidad de las acusaciones emitidas desde los rectorados se relacionan con simpatizar o pertenecer a partidos de izquierdas, ocupar cargos de confianza en los gobiernos republicanos, desarrollar una labor proselitista en favor del Frente Popular, etc., y sólo en contadas ocasiones las imputaciones son de carácter moral que, inclusive, se asocian a cuestiones políticas. Esta situación es similar a la sufrida por el profesorado de segunda enseñanza, aunque menos radicalizada si la contrastamos con el de universidad.

En lo que se refiere a las sanciones, en los varones imperan las que conllevan la separación definitiva o la suspensión temporal de empleo y sueldo, lo que certifica que estos profesores se consideran, por su vinculación ideológica con la República, elementos subversivos que es necesario extirpar de raíz, mientras que en las pocas profesoras sancionadas predomina la inhabilitación para cargos directivos y de confianza y el traslado forzoso fuera de la provincia, dado que se entiende que sus ideas y actuaciones no son relevantes y, por ello, no es necesario prescindir de ellas como docentes.

Quisiéramos recalcar, por otro lado, que la represión franquista no se conforma con la sanciones de carácter administrativo emanadas desde la maquinaria depuradora, sino que muchos de los profesores represaliados, a los cuales queremos homenajear desde aquí, sufren también encarcelamiento, como sucede con Vicente Pertusa Périz, que muere en prisión, Antonio Quintana Serrano, encarcelado al ser tomada Málaga por los golpistas, Antonio Gil Muñiz, preso en el penal del Puerto de Santa María, Francisco Castro Zafra, detenido al principio de la guerra, Cándido López Uceda, Ramón Carreras Pons... Finalmente, en algunos casos no basta con la cárcel y los detenidos son fusilados, como sucede con los profesores sevillanos José y Manuel León Trejo, el director de la Escuela Normal de Granada durante la República Agustín Escribano Escribano, y Enrique Esbri, numerario de la de Jaén hasta 1936 y diputado socialista, ejecutado y enterrado en la cuneta de algún camino cercano a la ciudad de León en torno, como se dijo, al 26 de julio de 1936. Pero a estos asesinatos se les pueden añadir los de otros muchos docentes, como el caso comentado de la universidad de Granada.

Deseamos concluir reiterando nuestro propósito de romper una lanza en favor de la memoria histórica, reivindicándola como un instrumento útil 
para comprender y decidir nuestro futuro, sin la intención de culpabilizar a nadie, sino, simplemente, de conocer, aceptar y vislumbrar lo sucedido, pues como señala el historiador Joaquín Prats «el conocimiento de la historia es mucho más transformador y revolucionario que recrearse en los recuerdos o en las memorias de unos contra otros». ${ }^{59}$

\section{Nota sobre los autores:}

Francisco Martín ZúÑIga. Sus principales líneas de investigación giran en torno a la historia de la escuela, el currículo y la educación en Andalucía, con especial interés en las políticas educativas en el siglo XX. Ha participado en diversos proyectos I+D+I. Su investigación en los últimos años se ha centrado en la depuración franquista del profesorado y en la actualidad, fruto de un nuevo proyecto, su prioridad investigadora se concentra en el papel del «Estado y la Iglesia en el control del profesorado no universitario (1857-1931)». Autor de varios libros y artículos en revistas científicas de impacto. En posesión de 2 sexenios.

IsABel Grana GIL. Actualmente sus líneas de investigación están orientadas en la historia de la educación en Andalucía, la educación de las mujeres en España y la depuración del profesorado de enseñanza secundaria (instituto y escuelas normales) durante el franquismo. Respecto a estos últimos ámbitos ha participado en diversos proyectos $\mathrm{I}+\mathrm{D}+\mathrm{I}$. Tiene numerosas publicaciones y está en posesión de 2 sexenios.

\footnotetext{
59 Joaquín Prats, «Memoria histórica y enseñanza de la historia», Escuela, 3877 (2010), 3.
} 
